Vol 9, No 1 (2021) | ISSN 2153-5914 (online) | DOI 10.5195/contemp/2021.323

http://contemporaneity.pitt.edu

\title{
Eight Views of the Sun Setting on the South Pacific
}

Kio Griffith

\begin{abstract}
About the Author
Kio Griffith is an interdisciplinary artist, independent curator, and arts writer working across themes of contemporary social issues, geopolitics, and migrating cultures. He engages with multimedia, contemporary craft, and technology-based media, including graphic design, sound and video, performance, coding, spatial design, and publishing. His work has been extensively exhibited internationally, including at the 2016 Aichi Triennale in Nagoya, Japan. Notable curatorial projects include his work as an emerging curator at LACE (Los Angeles Contemporary Exhibitions) in 2017, as a curator for the Japan Foundation and as guest editor-in-chief for the January/February 2015 issue of Artillery Magazine, which covers under-represented contemporary Asian feminist, nonbinary, and LGBTQ artists. His current projects include roles as co-founder of OOTE 41221 project space and Transit Republic, an art and socioanthropological publication. Griffith also works as an editor for Genzō, an intercultural photographic journal and independent curator and contributing editor for Fabrik (Los Angeles), Artscape (Tokyo), and Art Bridge Institute (Tokyo). Griffith holds a BFA from Otis/Parsons School of Design and an MFA from University of California, Santa Barbara. His work is included in private and museum collections, including the Los Angeles County Museum of Art.
\end{abstract}




\section{Eight Views of the Sun Setting on the South Pacific}

\author{
Kio Griffith
}

My thoughts and concepts often dwell on the crosscultural history that infuses images, sound, and the materiality of found and appropriated objects. I mine public and private family histories for personal experiences that generate insights into broader geopolitical contexts, even as they touch on modern-day issues of immigration and hyphenate identities.

My work channels psycho-geographical experiments to investigate personal referential space, challenging hierarchy, territory, and fidelity of sound. Cultural identities are woven through spatial-time zones, overwriting the history of the Other. This duality penetrates the projected double-image of identity and destabilizes borders.

My practice engages with a range of concepts-from projected visuals and invented languages to experiments in cross-cultural work. Interpretations are built and objects are formed from the most accessible materials: a sculpture spun out of poetic verse; bottles transmitting and receiving intermittent and insecure radio frequencies; myriad historical manifestos played in loops in the form of EP vinyl; the negotiation of familial history in the Pacific; and the ways that speech and sound can transition into noise, mondegreens, illusions, and then become reinterpreted into music or hybridized languages.

My work is an exploration of processed and shuffled information that uncovers meaning in a world of self-journalism, self-documenting, and archiving. Today, the general structural notion of "reading" is recalibrated continuously in reinvented languages, truncated communication strategies, aggregate associations, and "readings" between lines, faces, spaces, and the air surrounding us-in them, we continue to interrogate our context in the current world. 

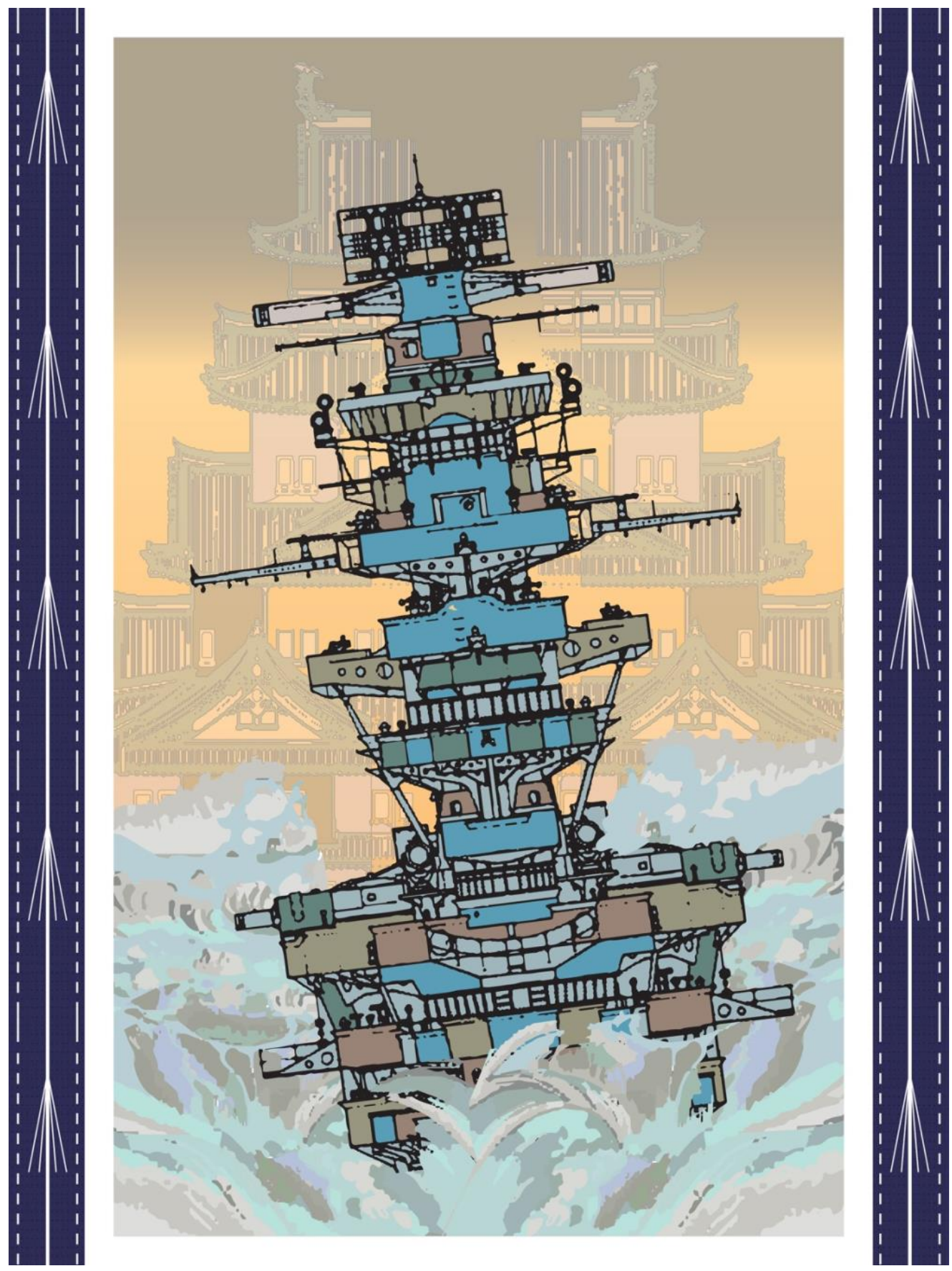

Figure 1

Kio Griffith, Eight Views of the Sun Setting on the South Pacific / Castle Ruins, 2020. Digital collage print on paper. 

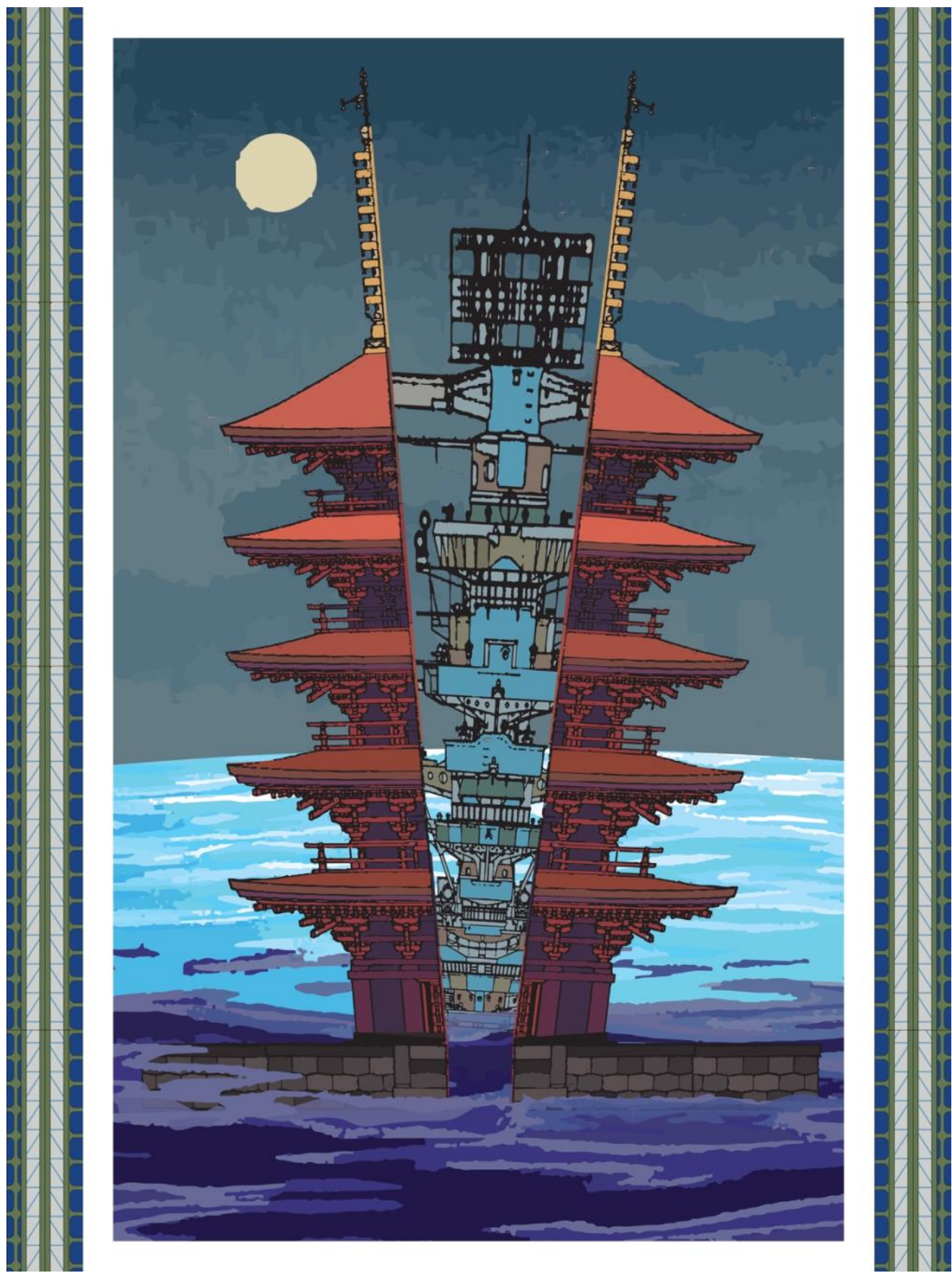

Figure 2

Kio Griffith, Eight Views of the Sun Setting on the South Pacific / Five Story Pagoda, 2020. Digital collage print on paper. 

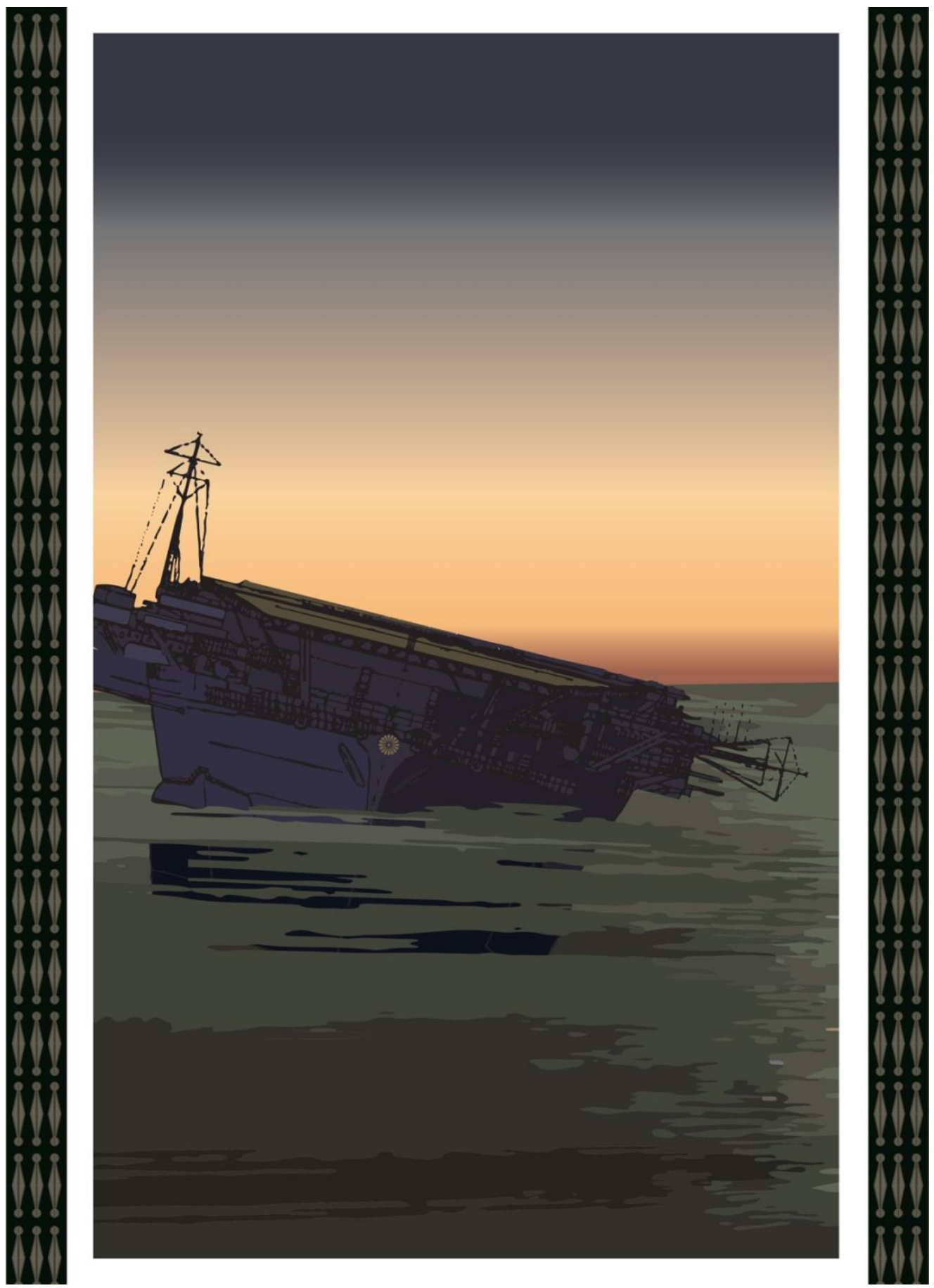

Figure 3

Kio Griffith, Eight Views of the Sun Setting on the South Pacific / IJN Shōhō, 2020. Digital collage print on paper. 

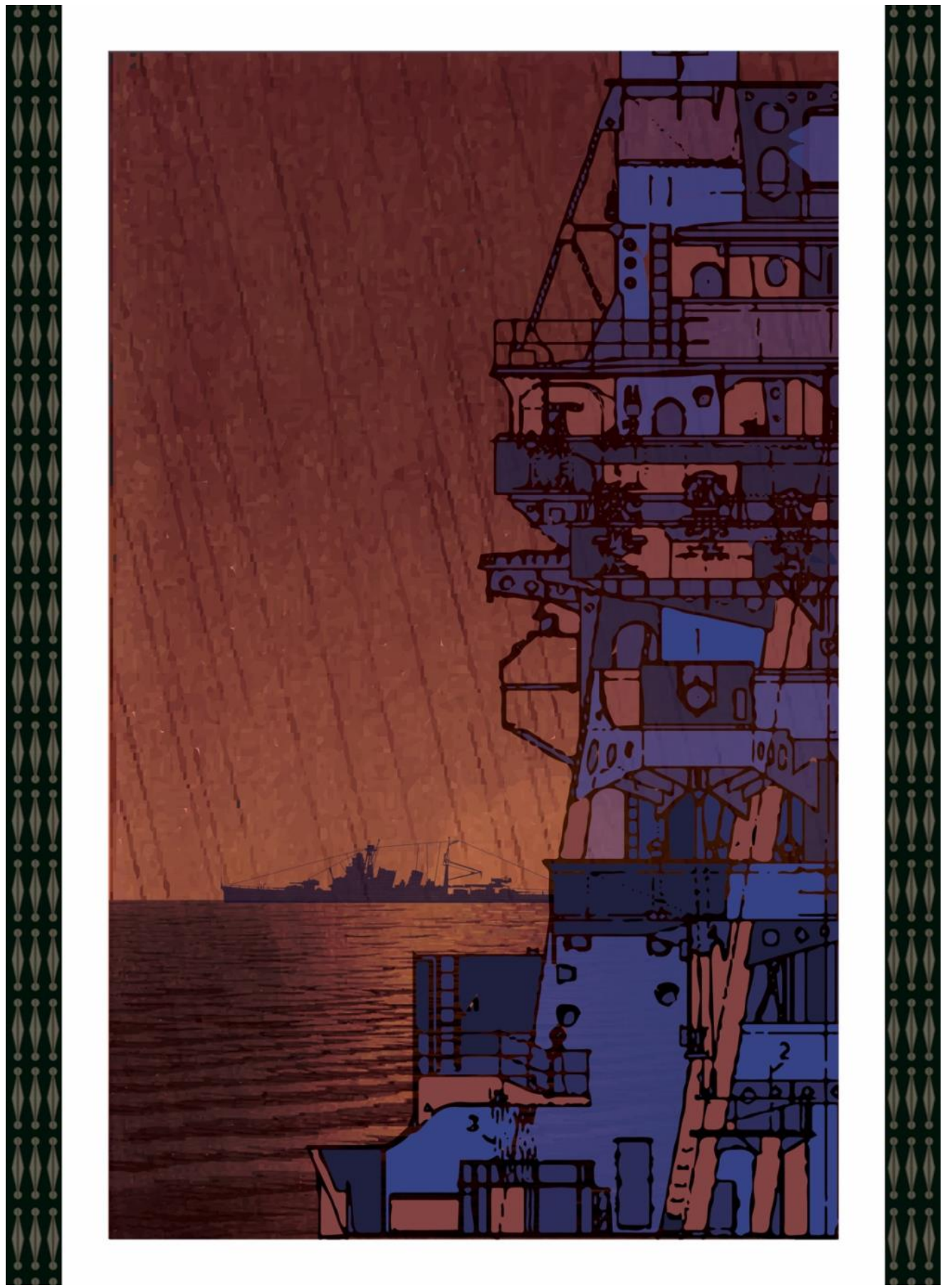

Figure 4

Kio Griffith, Eight Views of the Sun Setting on the South Pacific / Operation MO, 2021. Digital collage print on paper. 

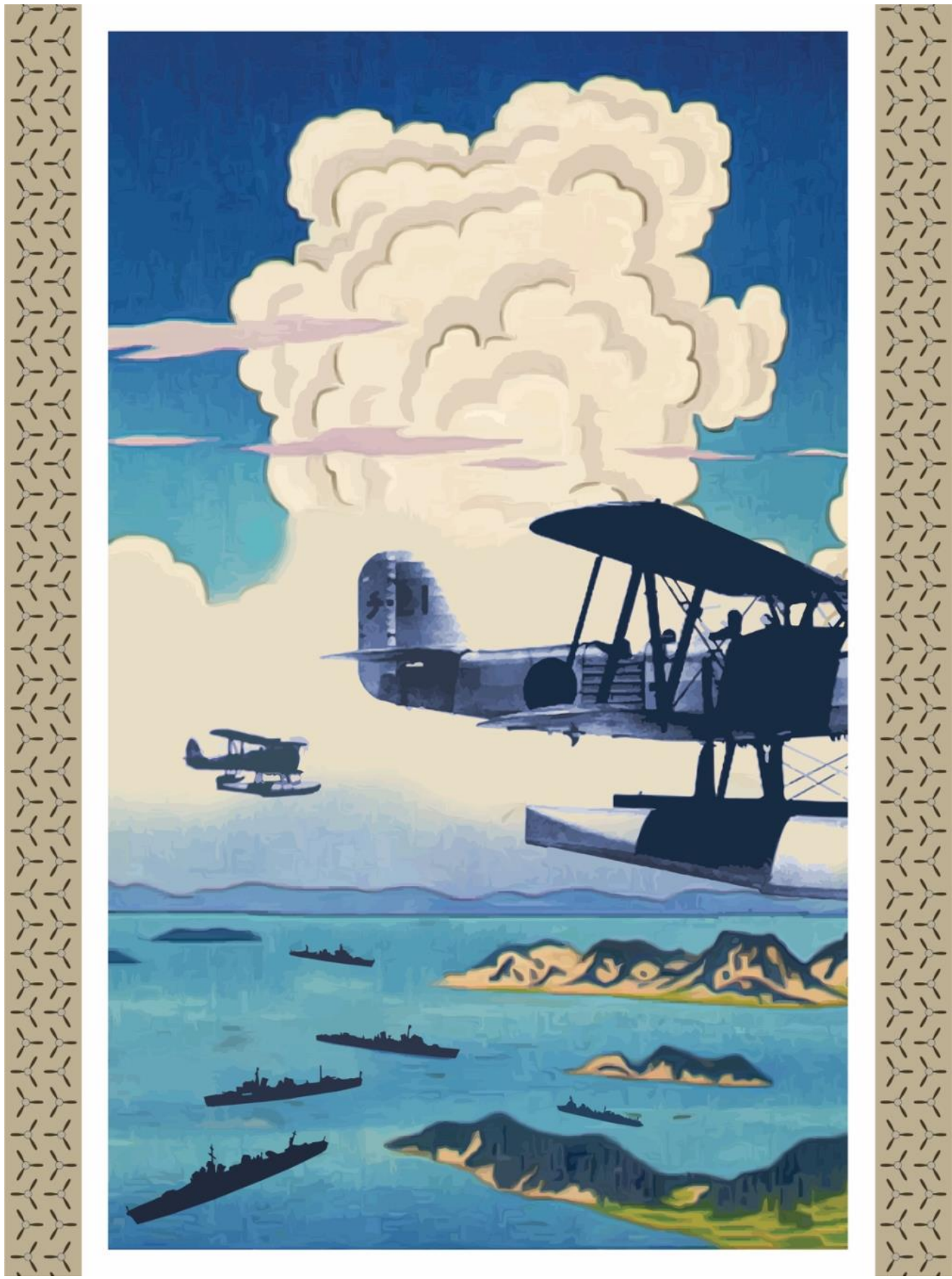

Figure 5

Kio Griffith, Eight Views of the Sun Setting on the South Pacific / Rabaul, 2021. Digital collage print on paper. 


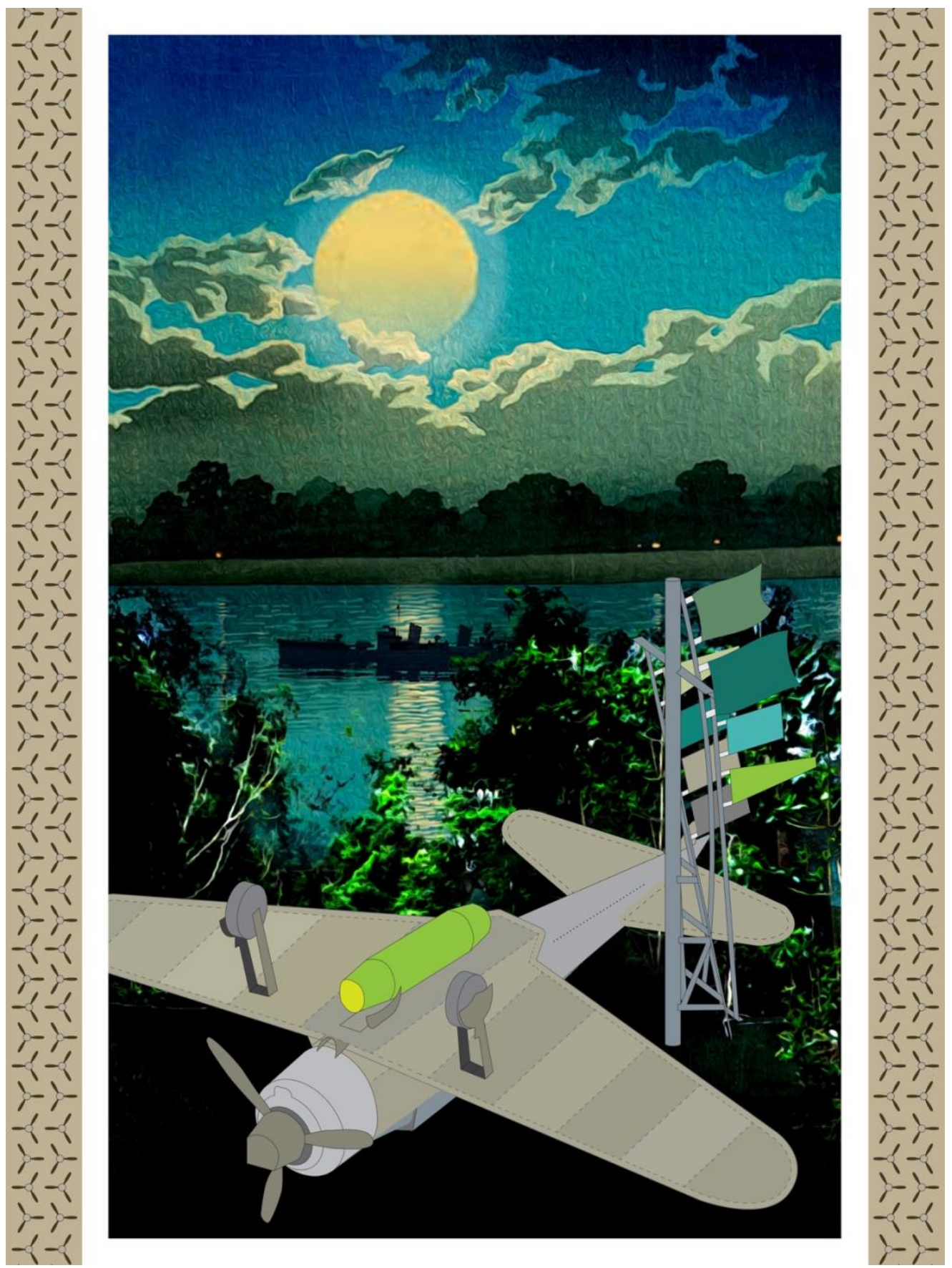

Figure 6

Kio Griffith, Eight Views of the Sun Setting on the South Pacific / Bougainville, 2021. Digital collage print on paper. 

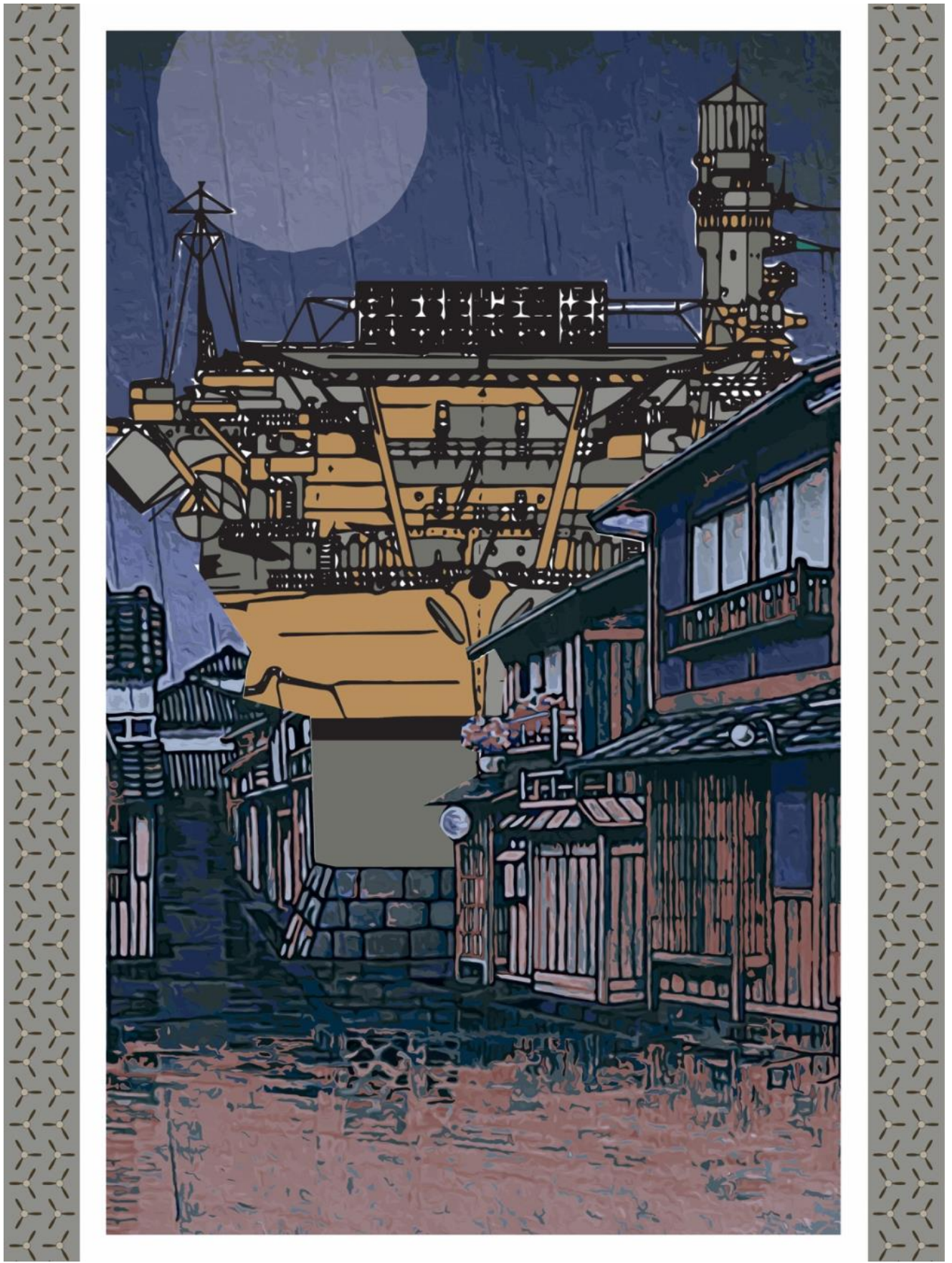

Figure 7

Kio Griffith, Eight Views of the Sun Setting on the South Pacific / The Bridge, 2021. Digital collage print on paper. 

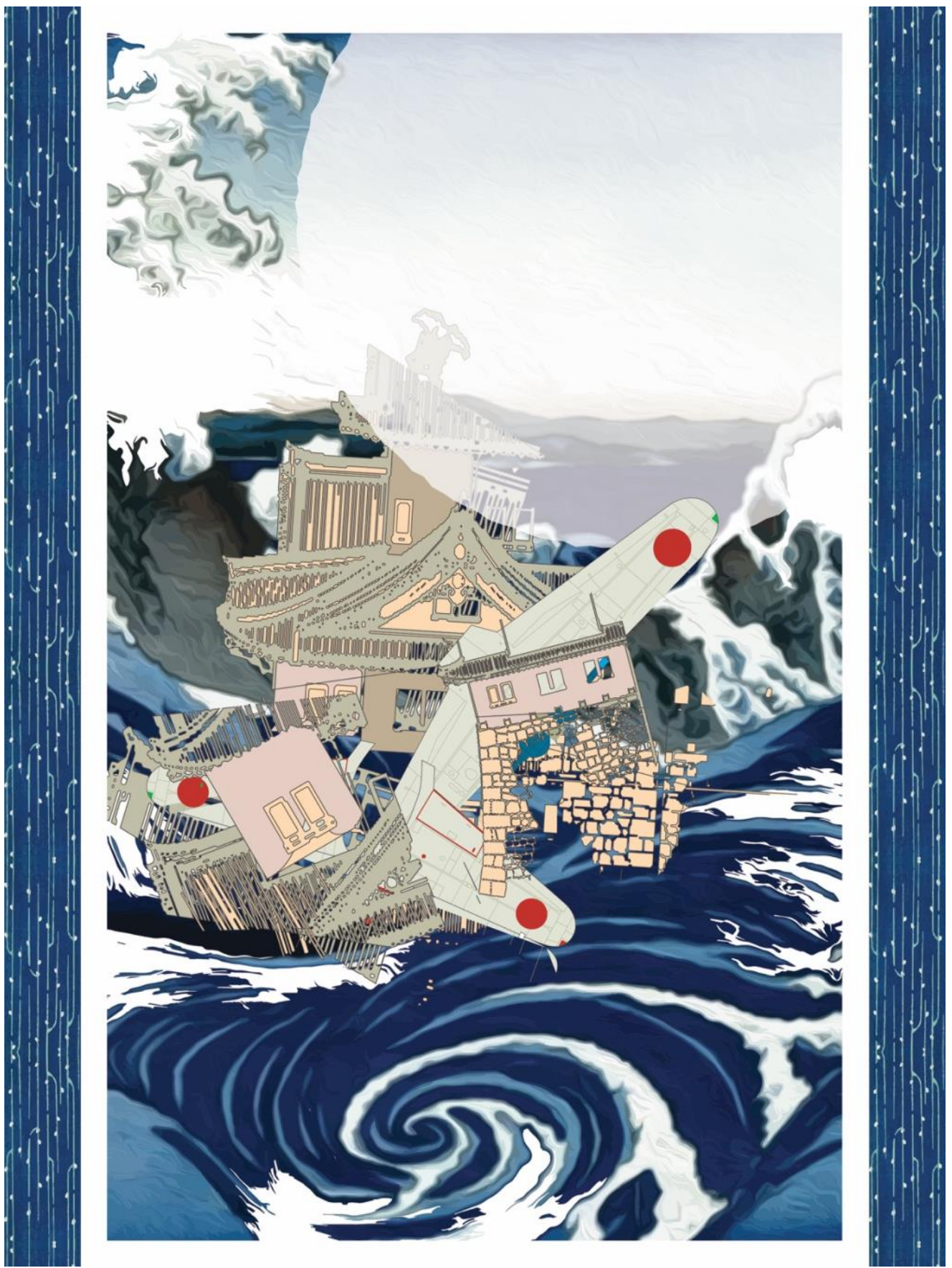

Figure 8

Kio Griffith, Eight Views of the Sun Setting on the South Pacific / Whirlpool Passage, 2021. Digital collage print on paper. 

4.0 United States License.

\section{UILIS D-Sulf}

This journal is operated by the University Library System of the University of Pittsburgh as part of its D-Scribe Digital Publishing Program, and is co-sponsored by the University of Pittsburgh Press. 